\title{
SWOT Analysis of the Old and New Campus of the University and Its Countermeasures
}

\author{
Xueyan Wang, Mengtian Li, Jianjun Cao ${ }^{\text {a }}$ \\ College of Geography and Environmental \\ Science Northwest Normal University \\ Lanzhou 730070, China \\ acaojj@nwnu.edu.cn
}

\begin{abstract}
With the implementation of the policy of enrollment expansion, there have emerged "new" and "old" campuses in many colleges and universities. On the bas is of the questionnaire surveyed in nine schools in Gansu, Shanxi, Henan and Hubei province, SWOT analysis method was used to compare the advantages and disadvantages and opportunities and threats between these two campus. The results showed that the advantages of the old campus mainly lie in its unique university culture atmosphere and convenient traffic conditions, and the disadvantage lies in its implemented infrastructure; in contrast, advantages of the new campus are disadvantages of the old campus, and disadvantages of it are advantages of the old campus. Therefore, the two can achieve their own development through strategic complementarity, giving full play to their respective advantages, seizing outside opportunities, and overcoming disadvantages and eliminating threats. However, if we assumed that only one campus could be conserved in the future due to the fact of the reduction in school-age students, then we found that most of the respondents were willing to giving up the new campus. The characteristics of the university itse If and the social and economic characteristics of the respondents have effect on conserving willingness of the campus. In short, the new and old campus must be developed respectively under the effect of the enrollment expansion. But with the reduction of the school-age population, the old and new campus will likely face a difficult choice.
\end{abstract}

Keywords-College enrollment; new and old campus; SWOT analysis; development strategy; reservations

\section{INTRODUCTION}

Martin Paul has divided the development of education into three stages: the gross enrollment rate is below $15 \%$ for the elite education, $15 \%$ to $50 \%$ for Volkswagen education, and 50\% for popular education ${ }^{[1]}$. The development process of education in China also shows the trend of "three stages" in general ${ }^{[2-4]}$. With the promotion of universal education and the implementation of the policy of enrollment expansion in universities, the teaching resources and geographical space of the original campus can't meet the needs of running a school any more. So universities began to expand. The expansion types mainly include self-expansion (such as Xi'an university of electronic science and technology), the merger and development model (Weishui campus of Chang'an university), the merger and replacement (Shanghai university), etc. ${ }^{[5]}$. Regardless of the type of extension, the focus is on expanding the new campus. As a result of the diversity of forms and structures of higher education running in the new campus, the new campus is bound to undergo transformational pains in terms of management system, discipline system, resources distribution, and cultural atmosphere ${ }^{[6]}$. Compared with the original campus, all aspects of the new campus are relatively new. The old campus not only has a superior geographical location and a strong humanistic discipline, but also witnesses the long course of university development. The campus has become an important content of campus culture construction, and some even become representative of urban culture ${ }^{[7]}$. In order to distinguish it from the new campus, this study refers to the original campus as the "old campus.".

Researchers conducted an in-depth analysis of the decision-making background of the policy of enrollment expansion in universities in our country and the reasons for the increase in the cost of change ${ }^{[8]}$. At the same time, some researchers have discussed the advantages and disadvantages of college enrollment expansion from different perspectives, such as the change of reproductive pattern of women of childbearing age ${ }^{[9]}$, the positive impact on employment ${ }^{[10]}$ and salary ${ }^{[1]}$, the negative impact on the marriage market ${ }^{[12]}$ and the real estate market ${ }^{[13]}$. But up to now, there has not been a comparative study on the product of expansion policy, namely, the new campus and the old school district. This is very unfavorable for the construction and development of the new old school district in China, especially in the case of the gradual shrinking of the source ${ }^{[14]}$. The choice of how to get out of this dilemma will have a profound impact on the structural adjustment and rational distribution of universities in China in the future. Therefore, this article will use the SWOT analysis method to compare the old and new campuses of universities to highlight their respective key opportunities and threats, so as to formulate development strategies that are more consistent with the objective conditions.

\section{SWOT ANALYSIS}

SWOT analysis, also known as situation analysis, is a strategic decision method proposed in the early 1980s. Through a comprehensive understanding of the internal environment and external opportunities and threats of things, a SWOT analysis matrix is finally constructed ${ }^{[15]}$ (TABLE I). In this analysis, S (Strength), W (Weakness), O (Opportunity) and T (Threat) respectively represent advantages, disadvantages, opportunities and threats ${ }^{[16-17]}$. On the whole, SWOT consists of two parts: the first part is SW, which is mainly used to 
analyze the internal conditions; the second part is OT, mainly used to analyze external conditions ${ }^{[18]}$.

TABLE I. SWOT MATRIX

\begin{tabular}{|c|c|c|}
\hline Internal environment & Advantage & Disadvantage \\
\hline External opportunities & S-O strategy & W-O strategy \\
\hline External threats & S-T strategy & W-Tstrategy \\
\hline
\end{tabular}

At present, many scholars at home and abroad have applied the SWOT method to natural resource management and environmental protection ${ }^{[19-20]}$, tourism management ${ }^{[21-22]}$ and Internet marketing ${ }^{[23]}$, etc., and obtained a series of results have practical significance. After years of development, SWOT analysis is not only used to analyze the strategic development of for-profit organizations such as enterprises, but also widely used to judge the status quo and development prospects of a large number of organizations involved in such as government agencies, and has become one of the main methods of system analysis ${ }^{[24]}$.

\section{SWOT ANALYSIS OF NEW AND OLd CAMPUS}

\section{A. The data source}

In order to thoroughly understand the current situation of the development of old and new campuses and to allow respondents to accept and understand the contents of the questionnaire, Before the formal questionnaire was formed, two small-scale pre-surveys were conducted at Northwest Normal University ${ }^{[25]}$. For the first time, open questionnaire was mainly used ${ }^{[26]}$, and in-depth interviews were conducted on the comprehensive functions of the new and old campus in different groups ${ }^{[27]}$.

On this basis, a semi-structured questionnaire was designed, and a second pre-survey was conducted. On the basis of two preliminary investigations, the formal questionnaire was formed after modification and supplementation ${ }^{[28]}$. The content mainly includes the basic social characteristics of the respondents, the advantages and disadvantages of the new and old campus districts, and willingness to retain old and new campuses.

From May to September 2016, nine schools of Gansu Province (Lanzhou University, Lanzhou University of Technology, Northwest Normal University, Lanzhou City College), Shaanxi Province (Xi'an University of Architecture and Technology, Xi'an Engineering University), Hubei Province (Hubei College of Arts and Sciences) and Henan Province (Henan University and Zhengzhou University) were selected respectively as the subjects of study. The questionnaire mainly adopts the face-to-face survey method to ensure the validity of the questionnaire as far as possible. A total of 1600 questionnaires were issued, 1455 were recovered, and the effective recovery rate was $91 \%$.

\section{B. The data processing}

Data processing was performed using Spss22.0 statistical software contingency table analysis and correlation analysis.

\section{Results}

The number of male and female respondents was similar, with 733 and 702 respectively. Of the male respondents, 323 were from the new campus and 410 from the old campus; of the female interviewees, 274 were from the new campus and 428 from the old campus (Fig. 1). Among the interviewees, the han nationality is about 1378, and the rest are hui, Tibetan and so on; Eighty-four percent were undergraduates, $14 \%$ were graduate students, and the rest were faculty or other staff (Fig. 2). Most respondents think the old campus has convenient transportation, but the construction planning and accommodation environment are poor, and the new campus is the opposite (TABLE II).

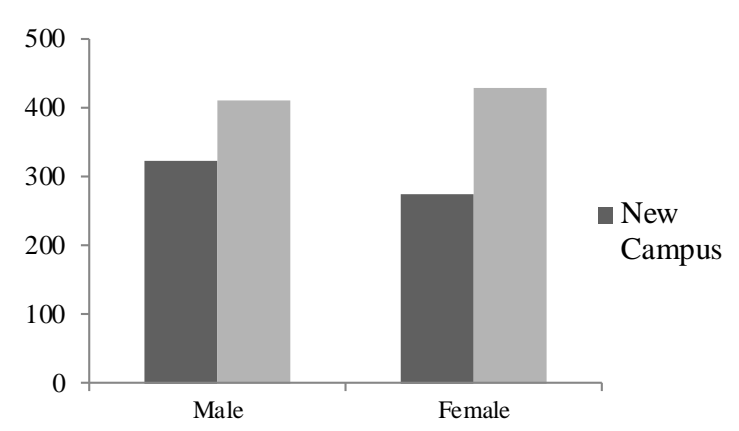

Fig. 1. Composition and genderstructure of respondents

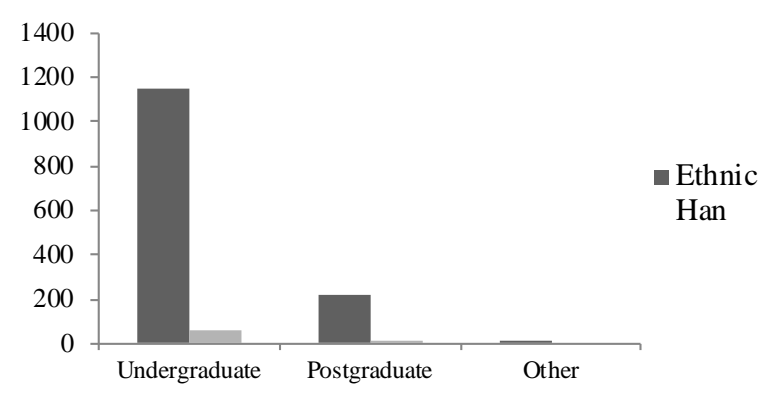

Fig. 2. National and educational structure of respondents

TABLE II. DIFFERENCES BETWEEN NEW AND OLD SCHOOL DISTRICTS

\begin{tabular}{|c|c|c|}
\hline Content (options can be multiple choices) & Number of people & proportion \\
\hline The utilization rate of old campus resources is high, and the utilization rate of the new campus is low; & 424 & $29 \%$ \\
\hline $\begin{array}{c}\text { The old campus building planning is chaotic and crowded, and the new campus planning is reasonable } \\
\text { and spacious; }\end{array}$ & 601 & $41 \%$ \\
\hline $\begin{array}{l}\text { The old campus is usually in the center of the city, with convenient transportation and the new campus } \\
\text { transportation is not convenient. }\end{array}$ & 742 & $51 \%$ \\
\hline Old campus facilities are old but complete, and new campus equipment is relatively new but not perfect; & 479 & $33 \%$ \\
\hline
\end{tabular}


Cont. to TABLE II

\begin{tabular}{|c|c|c|}
\hline \multicolumn{3}{|l|}{ Cont. to TABLE II } \\
\hline $\begin{array}{l}\text { The academic atmosphere of the old campus is relatively strong, and the new campus is relatively } \\
\text { desolate and lacks academic atmosphere; }\end{array}$ & 479 & $33 \%$ \\
\hline $\begin{array}{l}\text { Old school district has poor teaching and accommodation environment, and the new campus has a better } \\
\text { teaching and living environment; }\end{array}$ & 578 & $40 \%$ \\
\hline Other & 61 & $4 \%$ \\
\hline
\end{tabular}

\section{SWOT analysis of the old campus}

\section{1) Advantages of the old campus}

a) Rich historical context and strong learning atmosphere.

The term "wenmai" originated from the field of linguistics, which refers to the cultural essence and historical origin of the school's history ${ }^{[29]}$. In a sense, the accumulated culture of the old campus is not only a microcosm of the city culture, but also gives the alumni a sense of belonging and pride. Moreover, the teaching staff generally lives in the old campus. In the teaching process of the new campus, most teachers choose the form of "trans-school teaching"[30], and seldom communicate with students in face-to-face classes. Although the school is scheduled to answer questions at the end of the semester, the opportunities for communication are very limited due to trans-school teaching". The lack of communication is not conducive to the overall improvement of students' healthy growth and comprehensive quality ${ }^{[31]}$. In this survey, 33\% of respondents believed that the academic atmosphere of the old school district was stronger than that of the new campus, which was inseparable from its profound cultural heritage.

\section{b) High efficiency of resource utilization}

Although the old campus infrastructure is old, it is more concentrated and convenient to use. For example, the library is not only richer than the new campus, but also very convenient to borrow. Books on the new campus are generally available for appointment, and can be read only a week later. In this survey, 29\% of respondents believed that the resource utilization efficiency of the old school district is high, which is basically in line with the facts.

\section{c) Good service on and off campus}

The old school district is usually located in the city center, with convenient transportation. In addition, campus ecological function is also crucial. Due to the earlier construction of the old campus, the campus is full of greenery and vitality, which is not only conducive to purifying the air, reducing noise, but also providing teachers and students with confidence to study the academic environment. In this study, $51 \%$ of the respondents chose this item, indicating whether the convenience of transportation is an important basis for them to judge the reservation of new and old campus. Of course, the green environment near the city center is also a main reference index. The new campus is located in the urban and rural areas far away from the city center, with complex personnel, large security risks and inadequate planning and construction. When getting out of school, except for the endless farmland, only a strong rural culture left, which is contrary to the advanced campus culture philosophy of modern universities.

\section{2) Analysis of disadvantages of old school districts}

\section{a) The building is old and the space is crowded}

Although the old campus has a long history and profound cultural heritage, with the passage of time, the architectural style of the old school district lost its modern sense, and the architectural planning did not reflect a better human nature design. More importantly, land use efficiency is low, and this low-utilization spatial layout model has become overcrowded as the number of students' increases. In the survey, $41 \%$ of the respondents chose this item, indicating that many colleges and universities have this problem in the old campus and should draw the attention of relevant policy makers.

\section{b) Poor accommodation}

The facilities condition of colleges and universities is the bottleneck that restricts the supernormal and sustainable development of higher education institutions ${ }^{[31]}$. With the increase of the number of students, the accommodation conditions in the old school district can obviously not keep up with the requirements of the Times. Narrow space is difficult to place students' study and daily necessities neatly. If things continue this way, students' physical and mental health is extremely negative. In this survey, $40 \%$ of respondents chose this one, indicating that the accommodation problem in the old school district has become a common phenomenon.

\section{c) Large surrounding security risks}

With the appearance of "University Economic Circle ${ }^{[32] \text { ", }}$ the security issues around the old campus are becoming more and more prominent. According to the field investigation, the old campus of lanzhou university of science and technology has the advantages of various existing new campuses. However, the existence of a large number of floating population, such as nearby stations and vendors, has brought serious hidden dangers to the safety of teachers and students.

According to the actual situation of the development of the old campus, based on the SWOT, the SWOT strategy table of the development of the old school district is obtained (TABLE III).

\section{TABLE III. SWOT ANALYSIS STRATEGY OF THE OLD SCHOOL DISTRICT}

\begin{tabular}{|l|l|l|}
\hline Opportunity strategy threat & O1 Alumni's sense of belonging and spirit; & $\begin{array}{l}\text { O2 Location is located in the center of the city, } \\
\text { convenient transportation; }\end{array}$ \\
\hline $\begin{array}{l}\text { T1 The gradual improvement of the } \\
\text { comprehensive function of the new } \\
\text { campus }\end{array}$ & $\begin{array}{l}\text { SO(Utilize external opportunities to leverage internal advantages) } \\
\text { 1) Refine or rebuild infrastructure through alumni fundraising; } \\
\text { 2) Give full play to the public welfare function of the campus and outside opportunities to overcome } \\
\text { provide the surrounding residents with open facilities and venues. }\end{array}$ & $\begin{array}{l}\text { Worternal weaknesses) With the help of the economic circle } \\
\text { surrounding the old campus, New closed student } \\
\text { apartments were built through investment } \\
\text { promotion to improve student accommodation. }\end{array}$ \\
\hline
\end{tabular}


T2 In the pursuit of fashion and personal spaciousness, students gradually tend to study and live on the new campus.
1) Give full play to cultural heritage, Specially-designed teacher-student exchange center, Let them fully feel that the university lies in the inheritance of knowledge and full exchanges, not in the high-rises and spacious space caused by the respective array.

2) Schools provide certain transportation assistance or other incentives for teachers who frequently travel between the exchange center and the new campus. In order to mobilize their enthusiasm.
WT (Overcome internal weaknesses and avoid external threats.)

Emulate Harvard's transformation plan. Take the old building as the theme, transform the campus into a post-modern architectural style;

\section{B. SWOT analysis of the new campus}

\section{1) Advantages of the new campus}

Compared with the old campus, the new campus will focus on strengthening hardware facilities to make up for the insufficiency of educational resources, meet the needs of enrollment expansion, and enhance competitive advantages. For example, the new campus of Lanzhou University of Technology is one of the university campuses with the largest green area and the largest building area in gansu province, and in some ways, it has created a "new" vision.

Good accommodation is another advantage. In the process of attracting students to each other, universities and colleges do their best. Apart from strengthening the construction of software resources such as education quality, improving accommodation conditions is also one of the important contents of publicity and competition. Therefore, many colleges and universities new campus accommodation conditions are better than the old campus. In this survey, about $40 \%$ of respondents chose this one, indicating that hardware facilities have become an important indicator of students' choice of school.

\section{2) The disadvantage of the new campus}

\section{a) Insufficient campus culture atmosphere}

The new campus is established and developed on the basis of the old school district. It is the inheritance and innovation of the old campus culture. Whether it can inherit the history and culture of the school and the academic tradition is the key to the success of the new campus ${ }^{[33]}$. However, some colleges and universities do not know enough about the running mechanism of the new campus, and the management strategy is not sure. The pursuit of "acquisitionism" in the schooling work has the potential to lose its own original characteristics and advantages, and affect the school brand and image ${ }^{[34]}$. It can be seen that cultural deposits are of vital importance to the cultivation of students. About 33\% of respondents in this survey have recognized this problem

\section{b) Limited resource sharing.}

The spatial distance between old and new campuses has increased the cost of communication between campuses ${ }^{[35]}$, which has increased spending on non-teaching activities ${ }^{[36]}$. In addition, it is difficult for students in the new campus to enjoy the same opportunities for the use of school resources and transport facilities as students of this department, which has a negative impact on student learning and life ${ }^{[37]}$. This is in sharp contrast to the old school district.

\section{learning}

c) Single students form, blocked communication

The new campus is generally a junior student. Their values, world outlook and outlook on life have not yet been fully formed. In the absence of communication with senior students, it poses some difficulties for later development.

\section{d) Remote location and inconvenient transportation.}

The new campus mostly lies in the suburbs. Although there are school buses, they have caused inconvenience to teachers and students because of the limited number of school buses and the time-consuming and other reasons. The inconvenience of transportation not only affects the work and life of teachers and students, but also reduces the opportunities for students to contact with the society, which runs counter to the idea of campus regressive society advocated by universities. The following table is based on the actual situation of the development of the new campus. On the basis of SWOT, the SWOT strategy table of the development of the new campus is obtained. (TABLE IV).

\section{TABLE IV. SWOT ANALYSIS STRATEGY TABLE OF THE NEW CAMPUS}

\begin{tabular}{|c|c|c|}
\hline Opportunity strategy threat & O1 In the era of knowledge development & O2 Support from government policies \\
\hline $\begin{array}{l}\text { T1 The campus is generally located } \\
\text { in the suburbs and has a certain } \\
\text { influence on student safety. }\end{array}$ & $\begin{array}{l}\text { SO(Utilize external opportunities to leverage internal advantages) } \\
\text { 1) Utilize national support policies to continue to improve the construction } \\
\text { of comprehensive functions; } \\
\text { 2) Make use of the regional advantages to set up specialty specialties that } \\
\text { belong to the new campus. }\end{array}$ & $\begin{array}{l}\text { WO(Use outside opportunities to overcome } \\
\text { internal weaknesses) } \\
\text { 1) Establish digital network resource } \\
\text { sharing (e.g. curriculum resources, } \\
\text { academic activities); } \\
\text { 2) Regularly invite outstanding alumni to } \\
\text { conduct academic and living lectures. }\end{array}$ \\
\hline $\begin{array}{l}\text { T2 Geographically remote, there is } \\
\text { no attraction for investors. }\end{array}$ & $\begin{array}{l}\text { ST(Use internal advantages to counter external constraints) } \\
\text { 1) Strengthen closeness to nature education and broaden student } \\
\text { knowledge, Optimize the structure of ability, improve aesthetic taste and } \\
\text { civilization[38]; } \\
\text { 2) Copying of landmark buildings from the old campus will enable the new } \\
\text { campus to achieve consistency with the old campus in terms of architectural } \\
\text { planning and landscape design. In order to stimulate the cultural identity of } \\
\text { teachers and students. }\end{array}$ & $\begin{array}{l}\text { WT(Overcome Internal Disadvantages and } \\
\text { Avoid External Threats). } \\
\text { Establish "one person, one card real-name } \\
\text { system access school and dormitory" rules } \\
\text { and regulations to eliminate security risks. }\end{array}$ \\
\hline
\end{tabular}




\section{Reservation intention of the new and old campus.}

Through SWOT analysis, combined with the advantages and disadvantages of the new and old campus, as well as opportunities and threats, we can work out the corresponding development strategies respectively. But suppose that in the future when students' resources are extremely shrinking and it is difficult to guarantee the normal operation of the two campuses, which campus should be given priority? In order to understand this issue, we added this content in the questionnaire content. The results are as follows: Of the nine universities surveyed, more than $50 \%$ of the respondents in seven schools chose to retain the old campus. Only respondents from Hubei University of Arts and Sciences and Zhengzhou University preferred to keep the new campus (TABLE V). The reason why respondents from these two universities prefer to keep the new campus is that their new campus has the unique advantages of the old campus (such as cultural heritage and transport facilities), and it is relatively new and there is quite a brand-new feeling. For example, the new campus of Zhengzhou University has a history of 20 years. To a certain extent, it has accumulated part of the cultural heritage of the old campus, and its functions are relatively complete. Students rarely get into the old school district when they meet daily learning and living needs. They gradually developed feelings for the new campus. The same is true of the new campus of Hubei University of Arts and Sciences. In general, the longer a student spends studying and living in a certain school district, the more he/she tends to choose to retain this campus. This can also be demonstrated by the correlation between the respondent's campus and its willingness to retain the campus. In this study, the correlation coefficient of the interviewee's campus with its willingness to retain the campus was $r=0.28$ $(\mathrm{P}<0.01)$.

Except for the area where the respondent's campus affected the reservation of the school district, the analysis results of the contingency table show that the school district reservation is also related to the account and education (TABLE VI), and has nothing to do with gender. TABLE VI shows that students from rural households are more likely than urban students to keep the new campus. On the one hand, because most rural students were initially subjected to "Two outside the window, his ears heart read-only sages book" education concept and students lived in a single economic and cultural environment for a long time ${ }^{[39]}$. On the other hand, the new campus may bring some visual impact to students. Undergraduates are willing to retain the new campus while graduate students are willing to retain the old campus. The reason may be that undergraduates are younger and like new things, so they prefer to keep the new campus. The graduate student is willing to keep the old campus. This may be because graduate students tend to have a deeper cultural heritage as they mature gradually. The older, the stronger the sense of belonging and identity.

TABLE V. RESERVATION OF OLD AND NEW CAMPUSES

\begin{tabular}{|c|c|c|c|c|c|}
\hline \multirow{2}{*}{ Willingness to retain University } & \multicolumn{2}{|c|}{ Old Campus } & \multicolumn{2}{|c|}{ New Campus } & \multirow[t]{2}{*}{ total } \\
\hline & Sample number & Proportion & Sample number & Proportion & \\
\hline Lanzhou University & 121 & $76.6 \%$ & 37 & $23.4 \%$ & 158 \\
\hline Northwest Normal University & 53 & $59.6 \%$ & 36 & $40.4 \%$ & 89 \\
\hline Lanzhou University of Technology & 93 & $54.4 \%$ & 78 & $44.4 \%$ & 171 \\
\hline Lanzhou City University & 122 & $64.9 \%$ & 66 & $35.1 \%$ & 188 \\
\hline Xi'an University of Architecture and Technology & 145 & $72.5 \%$ & 55 & $27.5 \%$ & 200 \\
\hline Xi’an Polytechnic University & 79 & $78.3 \%$ & 22 & $21.7 \%$ & 101 \\
\hline Henan University & 168 & $84.0 \%$ & 32 & $16.0 \%$ & 200 \\
\hline Zhengzhou University & 93 & $47.0 \%$ & 105 & $53.0 \%$ & 198 \\
\hline Hubei University of Arts and Science & 48 & $32.0 \%$ & 102 & $68.0 \%$ & 150 \\
\hline total & 922 & $63.5 \%$ & 533 & $36.2 \%$ & 1455 \\
\hline
\end{tabular}

TABLE VI. SCHOOL DISTRICT WILLINGNESS TO RETAIN AND SOCIAL CHARACTERISTICS OF RESPONDENTS

\begin{tabular}{|c|c|c|c|c|c|}
\hline & & \multicolumn{2}{|c|}{ Percentage of retention intention } & \multirow[t]{2}{*}{ Chi-square value } & \multirow[t]{2}{*}{ significance } \\
\hline & & Old Campus & New Campus & & \\
\hline \multirow[t]{2}{*}{ Account } & city & $49.5 \%$ & $39.4 \%$ & \multirow{2}{*}{13.766} & \multirow{2}{*}{0.000} \\
\hline & Rural & $50.5 \%$ & 60.65 & & \\
\hline \multirow{2}{*}{$\begin{array}{l}\text { Education } \\
\text { background }\end{array}$} & Undergraduate & $79.9 \%$ & $91.7 \%$ & \multirow{2}{*}{35.164} & \multirow{2}{*}{0.000} \\
\hline & Postgraduate & $20.1 \%$ & $8.3 \%$ & & \\
\hline
\end{tabular}

\section{CONCLUSION}

In this paper, SWOT analysis method is used to study the old and new campuses of some colleges in the central and western regions. The results show that: overall, in the coexistence of strengths and weaknesses and opportunities and threats, new and old campuses should adopt different development strategies to sustain development in the context of continuous shrinkage of students in the future. For the old campus, the way to exert its inherent advantages and thus change the crowded space is the most important aspect of various development strategies. For the new campus, the way to seize the outside opportunities to tamp the campus culture is the only way out. Assuming that old and new campuses cannot co-exist due to shrinking students, priority should be given to protecting old campuses. Because of the need to make trade-offs between new and old campuses, $63.5 \%$ of respondents are willing to keep the old campus. Of course, the choice between old and new campuses is related to their own geographical location and surrounding environment, as well as the account and academic qualifications of the students. Therefore, the reservation issues in the old and new campuses are relatively complex and various factors need to be considered. A simple and one-size-fits-all policy must not be adopted. Each college should adapt itself to local conditions. 
Compared with the number of universities in the country, the number of universities involved in this study is very small, and whether the results are reliable requires further study and supplement. However, with the decline in the school-age population and the increase in the number of students studying abroad, the issue of retention in old and new campuses seems to be a national issue worth studying in the future.

\section{REFERENCES}

[1] Y. Chen, A Leap in the History of World Education--China Enters the Stage of Mass Higher Education, Journal of Tianjin University of Commerce, 2003,(4):11-12. (In Chinese).

[2] X. M. Zhou, The Path selection for elementary stages of Massification higher education in China, Xiangtan University, 2011. (In Chinese).

[3] R. W. Hu, H. S Zhang and X. Zhu, The State of Human Resources and Higher Educational Transformation Development in the Popularization Stage, Educational Research, 2014,(1):74-83. (In Chinese).

[4] L. G. Li, Transition of the popularization mode of Chinese higher education. Tsinghua Journal of Education, 2014,35(1):17-27. (In Chinese).

[5] J. Yang, Research on Campus Culture and Construction in New Campuses of Universities--A Case Study of Colleges and Universities in Xi'an, Shaanxi Province, Chang'an University, 2009. (In Chinese).

[6] Y. H. Xia, Transformation and Innovation: Reflections on problems encountered in running colleges and universities with multi-campuses, Journal of Wenzhou Normal College, 2003,(6):87-89. (In Chinese).

[7] Y. Y. Zhong, The Research of the Protection and Utilization about the Old Campus in the Development, Journal of Shandong Jianzhu University, 2010. (In Chinese).

[8] N. Kang, On Educational Decision and Institutional Innovation: A Case Study of '99 Universities' Enlargement of Enrollment Policy, Higher Education Research, 2000, (2): 31-38. (In Chinese).

[9] Q. S. Liang, J. Tian and H. J. Ji , College Expansion and Transition of Fertility Pattern:The Case of Hebei Province, Population Research, 2013,37(2): 41-53. (In Chinese).

[10]F. Deng and B. C. Sun, The impact of higher education expansion on graduate starting salary, Graduate School of Education, Beijing University, 2014,(2):132-138. (In Chinese).

[11]B. J. Ma, H. J. Cai and X. G. Yao, Higher education expansion. Ability heterogeneity and return to higher education------Evidences from CGSS, Economic Theory and Business Management, 2016,(6):45-56. (In Chinese).

[12] Y. W. Wu and Q. Liu, The impact of higher education expansion on the marriage market: Single women? Single men?, China Economic Quarterly, 2014,14(1):5-30. (In Chinese).

[13]C.Y. Zhang and X. L. Liu, Expanding College Enrolment VS Rising House Price, Chinese Journal of Population Science, 2014,(6):107-128. (In Chinese).

[14] C. J. Ye, C. T. Zhou and Z. G. Shao, The study on the soft landing of enrollment in local higher agricultural colleges and universities under the condition of shrink of the source of students, Industrial \& Science Tribune, 2011,10(12):172-173. (In Chinese).

[15]H. Weihrich, The TOWS Matrix--A Tool for Situational Analysis, Long Range Planning,1982,15(2):54-66.

[16] M. Hu and L. J. Chen, Research on the current situation of college students' entrepreneurship based on SWOT analysis and the education countermeasures, Education Exploration, 2008,(11):130-131. (In Chinese).

[17] H. Y Pan, A study of cultural tourism in Henan Province-Based on SWOT analysis method, He Nan University, 2013. (In Chinese).

[18] J. J. Cao, G. Z. Du,H. L. Wei and H. Wang, SWOT analysis on group-household grassland management in Maqu and strategies for future development, Pratacultural Science, 2009,26(10):146-149. (In Chinese).
[19]P. Diamantopoulou and K. Voudouris, Optimization of water resources management using SWOT analysis: The case of Zakynthos Island, Ionian Sea, Environmental Geology,2008,54(1):197-211.

[20]G. Santopuoli, M. Marchetti and M. Giongo, Supporting policy decision makers in the establishment of forest plantations, using SWOT analysis and AHPs analysis. A case study in Tocantins (Brazil), Land Use Policy,2016, 54:549-558.

[21]C. Yu, Study on the Sustainable Development Strategy of Wetland's Ecological Touris m Based on SWOT Analysis_-A Case of Zhangye National Wetland Park, Chinese Agricultural Science Bulletin, 2011,27(4):483-487. (In Chinese).

[22]B. Li, S. C. Dong, Z. H. Li and H. Y. Zheng, SWOT Analysis and Counter measures on Lanzhou Tourism Development, Journal of Arid Land Resources and Environment, 2009, 23(2):84-89. (In Chinese).

[23] Han Zhuangfei. A Research on the development of internet-finance take Alibaba Corp. As an example, Henan University, 2013. (In Chinese).

[24]K. F. Zhao, Research on the Optimization of Ideological and Political Education Environment in Colleges and Universities from the Perspective of SWOT Analysis, China University of Geosciences, 2010. (In Chinese).

[25] Y. Li, The technology of questionnaire design in the contingent valuation method, Environmental Protection Science, 2009,(6):25-28. (In Chinese).

[26] Adi force. Nur, Talking about the Related Techniques in Questionnaire Design, Statistical Science and Practice, 2012,(6):54-56. (In Chinese).

[27] X. Zhou, W. J. Hou, W. Sun and T. M. Li, User-Centered Design of Questionnaire-Application of in-depth interview and usability testing in quality control of questionnaire, Journal of Beijing University of Posts and Telecommunications(Social Sciences Edition), 2014, 16(2):83-89. (In Chinese).

[28] J. Li, How to Understand Society Better--On the Principles and Procedures of Questionnaire Design, Diao Yan Shi Jie, 2009,(3):46-48. (In Chinese).

[29]Z. C. Yang, Reflection on Some problems in the planning for the new campus, Journal Of Fujian Normal University(Philosophy and Social Sciences Edition ), 2004,(6):68-72. (In Chinese).

[30]D. Ma, Study on Campus Culture Construction in New Campuses of Universities, Changsha University of Science \& Technology, 2012. (In Chinese).

[31] R. Z. Gao and Y. Wang, Understanding and Thinking about the Teaching Management in University Campuses, Journal of China Women's Umvemity, 2009,21(1):123-126. (In Chinese).

[32] X. B. Li, An Analysis of the Construction of New Campuses in Colleges and Universities and Problems in China, Journal of Southwest University for Nationalities. Humanities \& Social Sciences, 2004,(5):343-345. (In Chinese).

[33]H. Song, On the Construction of Campus Culture in New Campuses in Different Places--Also on Campus Culture Construction in Zhuhai Campus of Sun Yat-sen University, Higher Education Research, 2002,(4):102-104. (In Chinese).

[34] J. Yao and Z. T. Wu, Reflection on the Operation of Multi-campus Universities, Journal Of Zhejiang Shuren University, 2011,11(6):97-100. (In Chinese).

[35] J. Y. Rao, The optimization study of traffic cost under the double campus running-As Chongqing Jiaotong University for example, Chongqing Jiaotong University, 2015. (In Chinese).

[36]Y. C. Chen and H. Shen, Brief review On the management of multi-campus university, Research On Education Tsinghua University, 2001,(2):111-118. (In Chinese).

[37]W. Yao and H. F. Wang, Multi-campus University: Experience, Problems and Reflections of Suzhou University, Journal of Suzhou University (Philosophy \& Social Science), 2007,(5):120-123. (In Chinese).

[38] S. H. Qi, Research on the Campus Culture Conformity after the Merger of Chinese Universities, Central China Normal University, 2004. (In Chinese).

[39] D. F. Li, L. Chen and W. W. Ning, A Study on the Different Adaptability of College Students from Different Regions and the Countermeasures, Journal of Southwest Jiaotong University, 2008, 9(3):77-82. (In Chinese). 